\title{
Imaging and imagination: understanding the endo-lysosomal system
}

\author{
Eline van Meel $\cdot$ Judith Klumperman
}

Accepted: 9 January 2008 / Published online: 15 February 2008

(C) The Author(s) 2008

\begin{abstract}
Lysosomes are specialized compartments for the degradation of endocytosed and intracellular material and essential regulators of cellular homeostasis. The importance of lysosomes is illustrated by the rapidly growing number of human disorders related to a defect in lysosomal functioning. Here, we review current insights in the mechanisms of lysosome biogenesis and protein sorting within the endo-lysosomal system. We present increasing evidence for the existence of parallel pathways for the delivery of newly synthesized lysosomal proteins directly from the transGolgi network (TGN) to the endo-lysosomal system. These pathways are either dependent or independent of mannose 6-phosphate receptors and likely involve multiple exits for lysosomal proteins from the TGN. In addition, we discuss the different endosomal intermediates and subdomains that are involved in sorting of endocytosed cargo. Throughout our review, we highlight some examples in the literature showing how imaging, especially electron microscopy, has made major contributions to our understanding of the endolysosomal system today.
\end{abstract}

Keywords Electron microscopy $\cdot$ Endosomes $\cdot$ Imaging · Lysosomal membrane proteins - Lysosomes · Mannose 6phosphate receptor $\cdot$ Protein sorting $\cdot$ trans-Golgi network

\section{Introduction}

Lysosomes are the terminal degradative compartments of the endocytic pathway. They receive extracellular compo-

E. van Meel · J. Klumperman $(\bowtie)$

Cell Microscopy Center, Department of Cell Biology,

University Medical Center Utrecht, AZU G02.525,

Heidelberglaan 100, 3584CX Utrecht, The Netherlands

e-mail: j.klumperman@ @mcutrecht.nl nents via endocytosis and intracellular material via autophagy, as well as via the biosynthetic pathway (Eskelinen 2005; Klionsky 2007; Luzio et al. 2007; Sachse et al. 2002a). By modulating the degradation of a multitude of proteins, lysosomes are key organelles in the regulation of cellular homeostasis. Moreover, these catabolic functions are complemented by a group of cell type-specific lysosome-related organelles, which store and/or secrete key factors involved in a diversity of functions, such as blood clotting, antigen presentation, pigmentation and alveolar surface tension regulation (dell'Angelica et al. 2000a; Raposo et al. 2007; Weaver et al. 2002). Because of their many functions, defects in lysosome functioning can have devastating consequences, as is illustrated by the rapidly growing number of human disorders displaying a primary or secondary defect in the lysosomal system. To date, lysosomal aberrations have been found in the 'classical' lysosomal storage disorders, as well as in muscular and neurological disorders, numerous types of cancer, immune-deficiency diseases and pigmentation-bleeding disorders (Futerman and van Meer 2004; Kroemer and Jäättelä 2005; Mohamed and Sloane 2006; Nixon 2005; Saftig et al. 2001).

Unraveling the intrinsic complexity of the endo-lysosomal system is a major challenge for cell biologists. Here, we will review some of the current insights in the mechanisms involved in lysosome biogenesis and functioning. Imaging of the endo-lysosomal system combined with imaginative visions has been instrumental for furthering the conceptual understanding of the endo-lysosomal system. Therefore, on the special occasion of the 50th anniversary of the Journal of Histochemistry and Cell Biology, we will also highlight some examples in the literature showing how imaging, especially electron microscopy (EM), has contributed to our understanding of the endo-lysosomal system today. 


\section{The discovery of the lysosome}

The famous story of the discovery of the lysosome reads as a compelling detective novel (Bainton 1981; de Duve 2005). A major question that was faced by the cell biological society of the fifties was how cells could exert proteolytic activity without being digested by autolysis. The first indications on the existence of lysosomes came from studies designed to answer an entirely different question-i.e. to clarify the action of insulin on the liver-in which acid phosphatase activity (nowadays known as a lysosomal activity) measurements were used as a control. A combination of experiments from the labs of Christian de Duve and Albert Claude led to the intriguing observation that acid phosphatase in fresh fractions, prepared by a relatively gentle protocol, showed astonishingly low activity levels. By contrast, samples that were obtained by a crude fractionation protocol or stored for some days before assaying showed elevated levels of phosphatase activity. When this same hideand-seek strategy was found for four additional hydrolytic enzymes, all with an acidic $\mathrm{pH}$ optimum and the same sedimentation characteristics as acid phosphatase, de Duve concluded that these enzymes must be contained together in particles surrounded by a membrane 'to prevent the enzymes getting out and the substrate getting in'. The term lysosome, for lytic particle or digestive body, was introduced (de Duve et al. 1955).

Novikoff, together with de Duve, provided the first EM pictures of these liver fractions that in addition to numerous mitochondria also showed an enrichment of electron dense bodies (Fig. 1). These were tentatively recognized as the 'pericanalicular dense bodies' previously found in intact liver cells (Novikoff et al. 1956). In these same years, Gomori had developed a protocol for acid phosphatase cytochemistry (Gomori 1952), which was subsequently optimized for EM by Novikoff, Holt, Barka and Anderson (Barka and Anderson 1962; Holt 1959; Novikoff 1961). The circle was closed when the acid phosphatase staining was applied to the ultrastructural level, thereby providing the direct evidence that acid phosphatase activity localized to the dense bodies of the liver parenchyma cells (Essner and Novikoff 1961) (Fig. 2), as well as similar bodies in various other cell types.

Another major clue was provided by Werner Straus. He found that 'droplets' of unknown function within the proximal tubules of the kidney contained reabsorbed (i.e. endocytosed) material as well as acid phosphatase activity and other lysosomal hydrolases (Straus 1954, 1956). This observation provided the first link between lysosomal digestion and endocytic uptake of extracellular material. Hence, the concept was born of the lysosome as a membrane-bound organelle that contains acid hydrolases involved in the digestion of substances that enter the cell

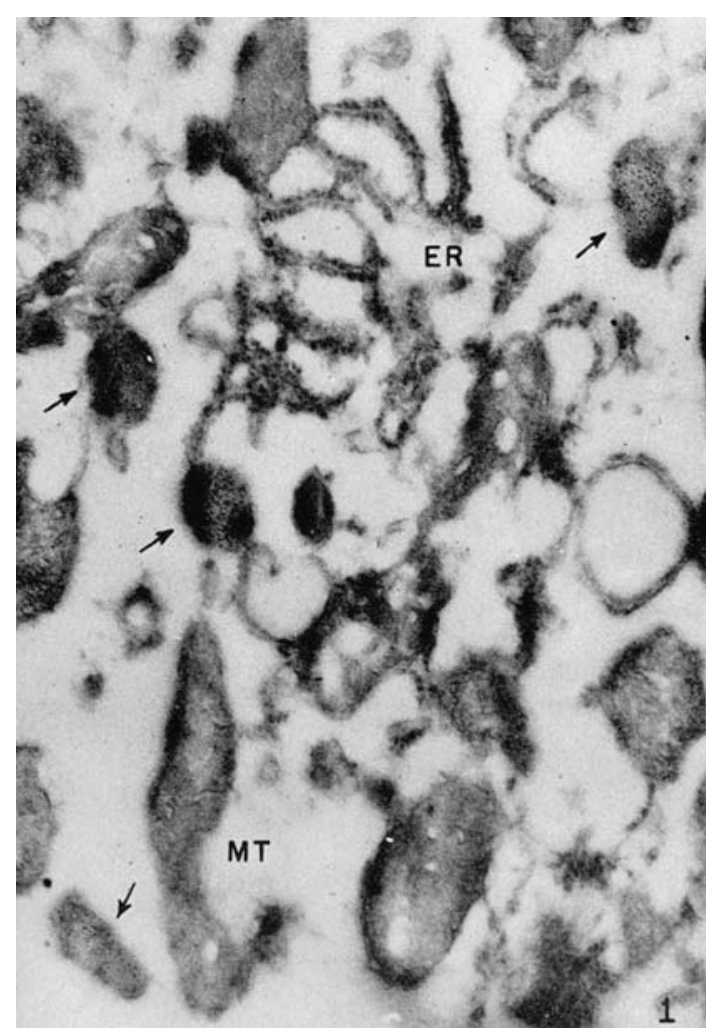

Fig. 1 Reproduction of the first electron micrograph ever that indicated the existence of lysosomes (arrows), as originally published in 1956 by Novikoff and colleagues. The sample represents a liver fraction that also contains mitochondria $(M T)$ and endoplasmic reticulum $(E R)$. Reproduced from Novikoff et al. (1956)

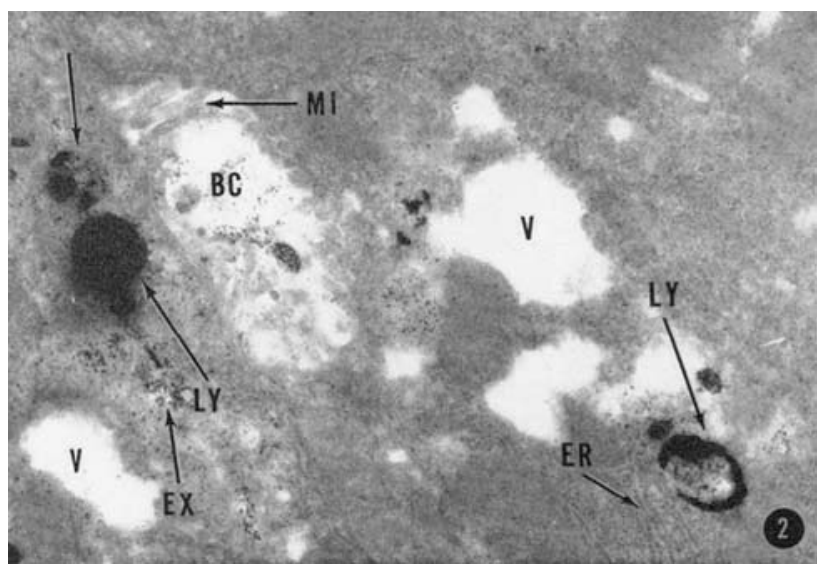

Fig. 2 Reproduction from Essner and Novikoff (1961). This picture shows for the first time at the ultrastructural level that acid phosphatase activity is localized in lysosomes $(L Y)$ of liver cells. $B C$ bile canaliculus, $E R$ endoplasmic reticulum, $E X$ extraneous precipitate, $M I$ microvilli, $V$ vacuole

via endocytosis (de Duve 1959). It explained that cells digest without autolysis by setting apart the degradative enzymes together with their endocytosed substrates in a membrane-bound compartment. The answer to the riddle was found. 


\section{The endocytic pathway in a nutshell}

Lysosomes receive extracellular substances for degradation via endocytosis: the invagination and pinching-off of membrane-bound vesicles from the plasma membrane (Fig. 3a). There are at least five highly controlled different entries into the cell, of which the 'classical' clathrin-mediated pathway is best-documented. However, the importance of non-clathrin-mediated pathways is becoming increasingly evident (Conner and Schmid 2003; Kirkham and Parton 2005; Mayor and Pagano 2007; Nichols 2003). Clathrin-mediated endocytosis begins with the sorting of receptors into a clathrin-coated pit at the plasma membrane, which then buds off to form a transport vesicle. These vesicles fuse with the first intracellular sorting station, the early endosome (Fig. 3a). Early endosomes have a mildly acidic pH that triggers the dissociation of some ligands from their receptors. Emptied receptors enter membrane tubules that emerge from the endosomal vacuole, resulting in transport via the recycling endosome back to the plasma membrane or, alternatively, the trans-Golgi network (TGN) (Fig. 3a). Receptors that remain ligand-bound are sequestered into small 50-80 nm diameter intraluminal vesicles (ILVs) that bud from the endosomal-limiting membrane into the endosomal lumen. Through a series of such vesicle fusion and fission events involving protein sorting, early endosomes gradually transform into late endosomes, a process called endosomal maturation. The formation of ILVs can continue up to the late endosome, which is why during endosomal maturation the number of these internal vesicles increases and late endosomes are often referred to as multivesicular bodies (MVBs, Fig. 3a). Degradation of cargo starts in late
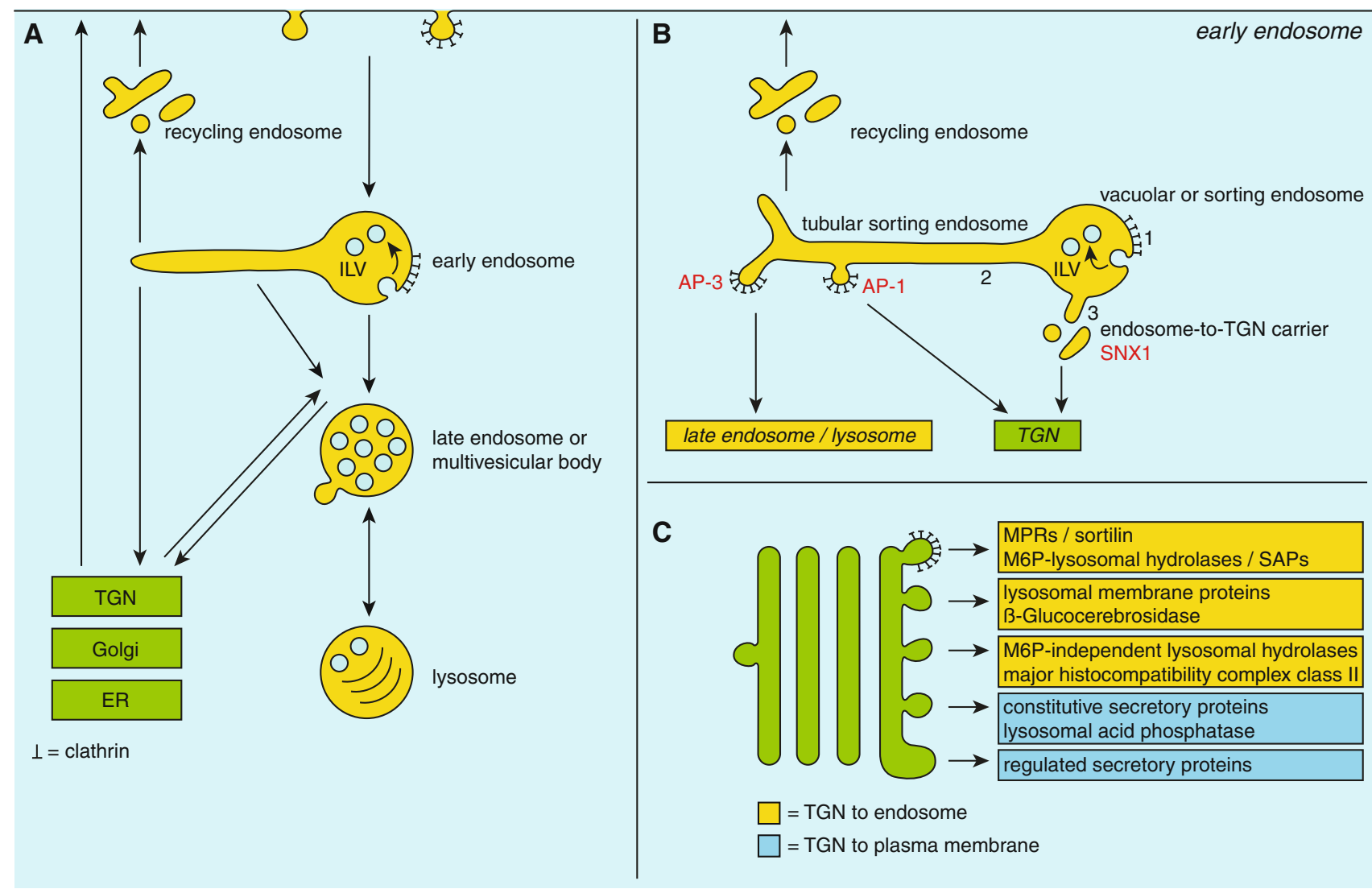

Fig. 3 Sorting and transport within the biosynthetic and endo-lysosomal pathways. a Schematic representation of the interplay between the biosynthetic pathway and endo-lysosomal system depicting the main endosomal compartments that are discussed in the text. b Detailed overview of the various sorting steps at the early endosome. At the endosomal vacuole or sorting endosome, receptor-ligand complexes destined for degradation accumulate in the bilayered clathrin coat (1), upon which they are sorted into intraluminal vesicles (ILV) that form by inward budding of the vacuolar limiting membrane. Recycling cargo by default enters the membrane tubules of the tubular sorting endosome (2) from which it can recycle back to the plasma membrane via the recycling endosome, or is actively sorted towards late endosomes/lysosomes (AP-3 pathway for lysosomal membrane proteins) or TGN (AP-1 pathway). A third exit from the vacuolar endosome is provided by the endosome-to-TGN carriers (3) that mediate SNX1-dependent recycling of MPRs and sortilin to the TGN. $\mathbf{c}$ From the TGN, multiple pathways arise that mediate transport to the endolysosomal system and plasma membrane. It is still an open question to what extent these pathways use different or overlapping molecular machinery and transport carriers. $A P$ adaptor protein complex, $E R$ endoplasmic reticulum, $M 6 P$ mannose 6-phosphate, $M P R$ mannose 6-phosphate receptor, $S A P$ sphingolipid activator protein, $S N X 1$ sorting nexin 1, TGN trans-Golgi network 
endosomes/MVBs and continues in the lysosome. Late endosomes/MVBs develop into lysosomes by multiple fusion and fission cycles (Futter et al. 1996; Luzio et al. 2007). After degradation of the lysosomal content, transporter molecules translocate sugars, amino acids and lipids across the limiting lysosomal membranes into the cytosol where they function as building blocks in the synthesis of new products.

\section{Defining early and late endosomes}

When studying the endo-lysosomal system, one is forced to continuously pose the question how to discriminate between the distinct endosomal intermediates. The distinction 'early' and 'late' endosomes often has too limited discriminating power to describe the dynamic continuum of the endo-lysosomal pathway. In a recent EM study (Mari et al. 2007), a novel method to distinguish early and late endosomes was introduced by combining morphological, kinetic and molecular criteria. Early endosomes are by definition accessible to internalized transferrin (Tf) that recycles to the plasma membrane. As a result, late endosomes contain only marginal levels of Tf. With this in mind, the number of ILVs within the endosomal vacuoles was correlated with the occurrence of internalized Tf. Tfpositive early endosomal vacuoles on average contained one to eight ILVs, whereas endosomal vacuoles with nine or more ILVs were mostly devoid of Tf and therefore designated as late endosomes. A similar analysis with various other established early endosomal marker proteins corroborated and extended this definition. For example, the early endosomal antigen 1 (EEA1) appeared to be connected with only the very early maturation stages of early endosomes (one to five ILVs), whereas Rab11 appeared only on the later maturation stages of early endosomes (four ILVs or more). The early endosomal markers Rab4 and Hrs were more evenly distributed. Although the interpretation of this study is currently limited to the cell line in which the analysis was performed, i.e. the human hepatoma cell line HepG2, these observations illustrate that distinct stages of endosomes can be better monitored with increasing means of analysis.

\section{TGN-to-endosome transport pathways}

To fulfill their degradative function, lysosomes must also receive lysosomal proteins. These are synthesized in the endoplasmic reticulum and Golgi complex, after which they enter the TGN (Fig. 3a). From the TGN, multiple pathways to the endosomal system arise, mediating delivery of essential components to various endosomal intermediates.
Thus, lysosomes receive their components via both the endocytic pathway and biosynthetic pathway.

Two classes of proteins together are essential for lysosomal functioning: the soluble lysosomal hydrolases and lysosomal membrane proteins. Each lysosomal hydrolase targets specific substrates for degradation and presently more than 50 different types are known. The heavily glycosylated lysosomal membrane proteins encompass a group of proteins with various functions. The major lysosomal membrane proteins (Marsh et al. 1987) are the lysosomeassociated membrane proteins (LAMP)- 1 and -2 , the lysosomal integral membrane protein (LIMP)-2 and the tetraspanin CD63 [originally identified as platelet-activating glycoprotein (Pltgp40) and also often referred to as melanoma-associated antigen ME491, LIMP-1 or LAMP-3]. Initially, lysosomal membrane proteins were thought to mainly play a role in lysosomal stability and integrity, but currently new functions emerge involving chaperone-mediated autophagy and macroautophagy (reviewed by Eskelinen et al. 2003). Thus, the proper targeting of lysosomal proteins from the TGN to the endo-lysosomal system is an essential process in the biogenesis and maintenance of lysosomes. The best-known pathway for TGN-to-endosome transport is the delivery of soluble lysosomal hydrolases by the $300 \mathrm{kD}$ cation-independent (CI) and $46 \mathrm{kD}$ cationdependent (CD) mannose 6-phosphate receptors (MPR) (Kornfeld and Mellman 1989; von Figura 1991). However, as will be outlined in the next paragraphs, increasing evidence indicates the existence of multiple additional or alternative pathways from the TGN to endosomes.

\section{MPR-dependent transport of soluble lysosomal hydrolases}

Both the CI and CD-MPR are present in almost all mammalian cell types. The lumenal domain of the CI-MPR is composed of 15 repetitive units, with two mannose 6-phosphate (M6P)-binding sites, whereas the CD-MPR has a lumenal domain of 159 amino acids, resembling one such unit, and has a single M6P-binding site. The M6P-binding sites recognize M6P-moieties, which are specifically present on the precursor forms of newly synthesized lysosomal hydrolases. Both receptors predominantly function as non-covalently bound homodimers. A specific role for each MPR in the targeting of lysosomal hydrolases has not been established, but distinct lysosomal hydrolases can exhibit different affinities for CI or CD-MPR (Qian et al. 2008; Sleat and Lobel 1997). CI-MPR can endocytose extracellular lysosomal hydrolases, whereas under physiological conditions CD-MPR is not involved in endocytosis. CD-MPR shows enhanced ligand binding in the presence of divalent cations (Hoflack and Kornfeld 1985a, b). Interestingly, the CI-MPR 
also has several other functions; it regulates the levels of circulating insulin-like growth factor II by binding it at the plasma membrane for delivery to lysosomes. Furthermore, it facilitates the activation of the precursor of transforming growth factor- $\beta 1$, which is a growth inhibitor, and also binds retinoic acid, thereby mediating retinoic acidinduced apoptosis and growth inhibition, further supporting the idea that CI-MPR could be a tumor suppressor (reviewed by Ghosh et al. 2003a).

Together, the two MPRs mediate the targeting of the huge majority of newly synthesized lysosomal hydrolases from the TGN to the endo-lysosomal system (Fig. 3c) (Hoflack and Kornfeld 1985a, b; Sahagian et al. 1981). In steady state, both CD and CI-MPR have been localized by immuno-EM to the TGN, plasma membrane, endosomes and associated vesicles (Bleekemolen et al. 1988; Geuze et al. 1984, 1985; Griffiths et al. 1988; Klumperman et al. 1993, 1998). Sorting of MPRs at the TGN was long thought to predominantly depend on binding to the heterotetrameric adaptor-protein complex (AP)-1, which also mediates the recruitment of clathrin (Fig. 4). The discovery of the Golgilocalized, $\gamma$-ear-containing, Arf-binding family of proteins (GGA) as clathrin adaptors changed this view (Boman et al. 2000; dell'Angelica et al. 2000b; Hirst et al. 2000; Poussu et al. 2000). GGAs are monomeric proteins and three different forms are known in mammals, GGA1, GGA2 and GGA3. GGAs and AP-1 might function in parallel to generate distinct MPR-containing vesicles at the TGN, thereby allowing delivery to different endosomal compartments. Alternatively or additionally, GGAs may facilitate entry of MPR into clathrin-coated vesicles by interacting with AP-1 . A major clue in favor of the latter hypothesis was provided by immuno-EM showing that GGAs and AP-1 colocalize in the same clathrin-coated TGN buds (Doray et al. 2002; Puertollano et al. 2003). Furthermore, the three GGAs were found to interact with each other and also to bind directly

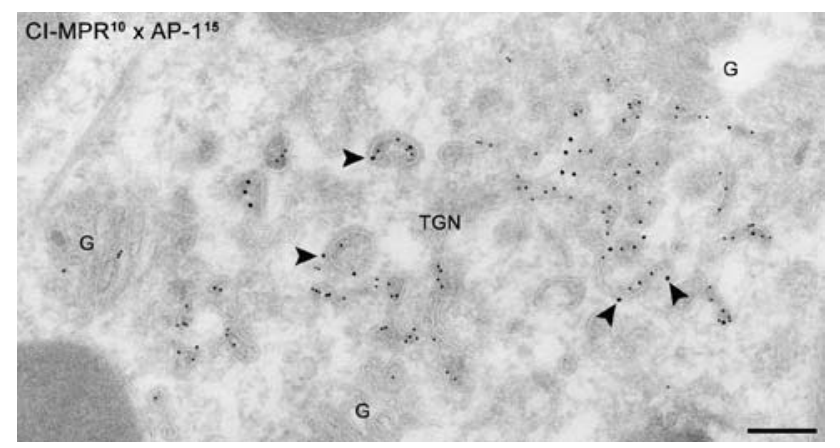

Fig. 4 Immuno-EM of a human hepatoma cell (HepG2) showing the occurrence of CIMPR (represented by $10 \mathrm{~nm}$ gold particles) in $A P-1$ (represented by $15 \mathrm{~nm}$ gold particles) coated $T G N$ membranes (arrowheads). CI-MPR and AP-1 positive membranes also show the characteristic cytoplasmic dense coat indicative for the presence of clathrin. The $T G N$ area is enclosed by distinct golgi stacks $(G)$. Bar, $200 \mathrm{~nm}$ with their hinge domain to the $\gamma$-ear domain of AP- 1 . Depletion of each GGA resulted in decreased levels of the other GGAs, their redistribution to the cytosol and impaired sorting of CI-MPR and the lysosomal hydrolase cathepsin D (Doray et al. 2002; Ghosh et al. 2003b). However, these findings do not rule out the possibility that different adaptor proteins can also act separately to a certain extent. Interestingly, it is not precisely known where the MPRs deliver their bound ligands. A small percentage of the MPRs travels to the cell surface, from where they are internalized by clathrin-mediated endocytosis and routed to the early endosomes. However, the majority takes a direct intracellular pathway to the endo-lysosomal system, and it is generally believed that both early and late endosomes can be recipients for TGN-derived MPR. The involvement of multiple adaptors could provide a means to establish these distinct pathways.

\section{MPR-independent transport of soluble lysosomal hydrolases}

In addition to the well-characterized MPR pathway, several additional transport pathways for lysosomal hydrolases exist (Fig. 3c). For example, the lysosomal hydrolases lysosomal acid phosphatase and $\beta$-glucocerebrosidase do not acquire M6P residues and their transport is not depending on MPRs (Aerts et al. 1988; Waheed et al. 1988).

Lysosomal acid phosphatase is a type I transmembrane protein that follows the constitutive secretory pathway to the plasma membrane and reaches the lysosome via endocytosis. In lysosomes, the transmembrane precursor is processed into a soluble form, but both proteins are enzymatically active (Waheed et al. 1988). Lysosomal acid phosphatase contains the tyrosine-based motif YRHV in its cytosolic domain, which is required for endocytosis, but does not mediate direct TGN-to-endosome targeting (Obermüller et al. 2002; Peters et al. 1990; Pohlmann et al. 1988).

$\beta$-Glucocerebrosidase has no membrane spanning domain (Erickson et al. 1985). After synthesis, it is glycosylated upon which it becomes membrane-associated (Rijnboutt et al. 1991). The machinery required for proper transport of $\beta$-glucocerebrosidase was long unknown. Recently, Paul Saftig and colleagues unexpectedly identified the lysosomal membrane protein LIMP-2 as a specific receptor for $\beta$-glucocerebrosidase. LIMP- 2 binds $\beta$-glucocerebrosidase in a $\mathrm{pH}$-dependent manner, enabling association in the ER and guiding it all the way to the lysosome, where the complex likely dissociates because of the acidic pH (Reczek et al. 2007). Whether LIMP-2 recycles between endosomes and TGN is not known. This study for the first time implies a lysosomal membrane protein in the 
transport of a lysosomal hydrolase. It will be very interesting to establish whether LIMP-2 acts as a more general binding partner for lysosomal hydrolases. In addition, characterization of the molecular machinery required for transport will provide further insight into this TGN-to-endosome transport pathway.

Lysosomal hydrolases that are normally modified with a M6P residue can also traffic in an MPR-independent way to the lysosomes (Fig. 3c). This became apparent by comparing different cell types from patients with I-cell disease, also known as Mucolipidosis type II. In this disease, soluble lysosomal hydrolases do not acquire M6P groups due to a deficient activity of the enzyme GlcNAc-phosphotransferase (Hasilik et al. 1981; Reitman et al. 1981). As a consequence, the lysosomal hydrolases follow the default constitutive pathway to the plasma membrane (Fig. 3c) and are thus secreted. However, in cells of non-mesenchymal origin, most lysosomal hydrolases are still targeted correctly to the lysosome (Fig. 5) (Little et al. 1987; Owada and Neufeld 1982; Waheed et al. 1982), suggesting the existence of alternative pathways. The same phenomenon was observed in a very recently established mouse model system for I-cell disease, achieved by GlcNAc-phosphotransferase knockout (Gelfman et al. 2007). Furthermore, in mice that are deficient of both MPRs, the intracellular activities of several lysosomal hydrolases are comparable to the control situation (Dittmer et al. 1999). These findings indicate that lysosomal hydrolases can follow a pathway to the lysosome that is not mediated by MPRs.

The mechanisms and pathways of MPR-independent transport are still poorly defined. Recent studies, however, have implicated a role for the multiligand receptor sortilin as an alternative receptor for a subset of lysosomal proteins, called sphingolipid activator proteins (SAPs), which are non-enzymatic cofactors required for the degradation of glycosphingolipids. Two SAPs are known; the precursor protein prosaposin, which renders saposin $\mathrm{A}, \mathrm{B}, \mathrm{C}$ and $\mathrm{D}$ after proteolysis, and $\mathrm{G}_{\mathrm{M} 2}$ activator protein (AP), an essential cofactor for $\beta$-hexosaminidase A. Studies from Lefrancois and colleagues have shown that sortilin interacts with both prosaposin and $\mathrm{G}_{\mathrm{M} 2} \mathrm{AP}$, which is independent of M6P tags, whereas depletion of sortilin induced their secretion (Lefrancois et al. 2003). It remains to be established, however, whether sortilin is the exclusive receptor for SAPs, or whether MPR has an additional role in their transport. Interestingly, sortilin, together with SorLA and SorCS1-3, forms a protein family sharing homology to the lumenal domain of the yeast vacuolar sorting protein Vps10p, which directs carboxypeptidase $Y$ to the vacuole (Marcusson et al. 1994). Immuno-localization studies positioned sortilin predominantly in endosomes and the TGN (Mari et al. 2007), where it colocalized with CI-MPR in AP-1 and GGA3 positive clathrin-coated transport carriers,

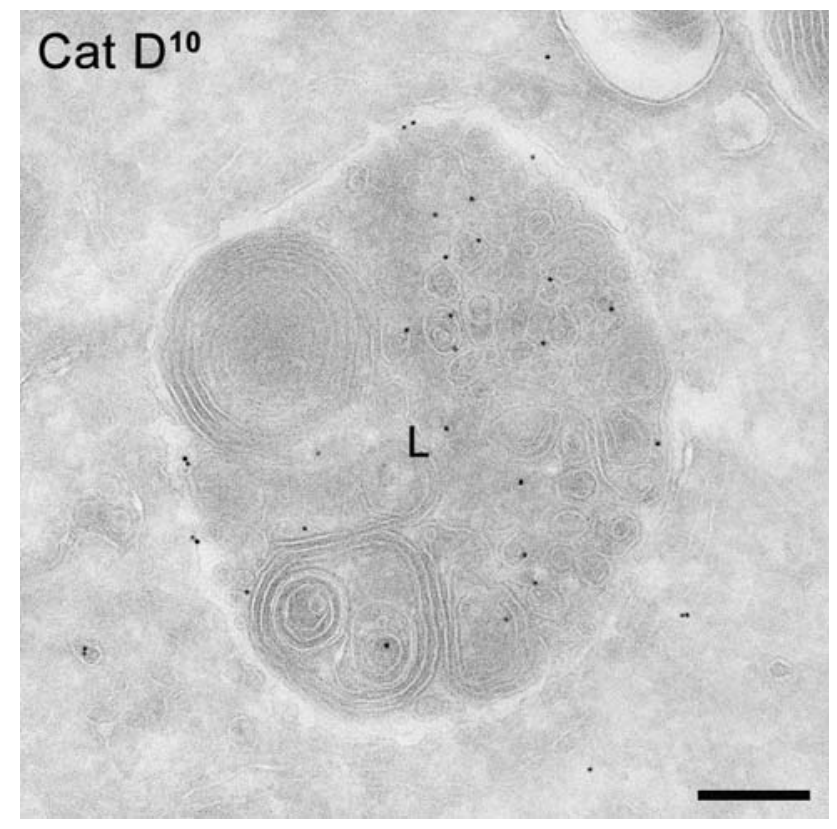

Fig. 5 Immuno-EM of a B lymphoblast derived from a patient with I-cell disease showing a lysosome $(L)$ positively labeled for the lysosomal hydrolase cathepsin $D$ (represented by $10 \mathrm{~nm}$ gold particles). This picture indicates that although the MPR pathway is impaired in these cells, lysosomal enzymes can still reach lysosomes. Bar $200 \mathrm{~nm}$

indicating that sortilin and MPRs travel via the same carriers to the endo-lysosomal system. Currently, the functions of the SorCS-subgroup are unknown, but since SorCS3 is predominantly localized at the plasma membrane it is unlikely to be involved in TGN-to-endosome trafficking (Westergaard et al. 2005). Whether sortilin or possibly SorLA could act as alternative receptors for lysosomal hydrolases is still unclear.

\section{TGN-to-lysosome transport of lysosomal membrane proteins}

Lysosomal membrane proteins that exit the TGN can be transported to lysosomes following either a direct or indirect pathway, involving passage over the plasma membrane. Virtually nothing is known about the carriers and molecular machinery that mediate the direct route of lysosomal membrane proteins to the lysosomes. Moreover, the contribution of this pathway remains debated (Carlsson and Fukuda 1992; Janvier and Bonifacino 2005). Important for the sorting of lysosomal membrane proteins to lysosomes are the tyrosine and dileucine-based consensus motifs within their cytosolic tails. LAMP-1, LAMP-2 and CD63 (LIMP-1) all bear a YXXØ motif, with an essential tyrosine residue, hydrophobic XX residues and the $\emptyset$ residue being a bulky hydrophobic amino acid (reviewed by Bonifacino 
and Traub 2003). The YXXØ motif is required for endocytosis at the plasma membrane, but has also been implicated in the direct targeting from TGN to lysosomes. For TGN sorting, however, additional characteristics seem to be required; a glycine residue preceding the critical tyrosine, the $\mathrm{XX}$ residues being acidic and the entire motif positioned six to nine residues from the transmembrane domain.

LIMP-2, the recently identified receptor for $\beta$-glucocerebrosidase, has a dileucine-based sorting motif DXXLL, also referred to as acidic cluster-dileucine motif, which has also been implicated in both internalization and TGN-tolysosome targeting. The YXX $\varnothing$ motifs are recognized by the $\mu$ subunits of AP-1, AP-2, AP-3 and AP-4 and the DXXLL motif by the VHS domain of the GGAs (reviewed by Bonifacino and Traub 2003). The role of adaptor proteins in TGN sorting of lysosomal membrane proteins remains to be established. Segregation of LAMP-1 into AP1 positive vesicles was observed in a biochemical study and also confirmed by immuno-EM, indicating exit from the TGN in clathrin-coated vesicles (Höning et al. 1996; Hunziker and Geuze 1996). However, sorting of LAMP-1 is not strictly dependent on AP-1. In mice lacking the $\mu 1 \mathrm{~A}$ subunit, which impairs AP-1 binding and clathrin assembly at the TGN, there was no significant increase in plasma membrane levels of LAMP-1 (Meyer et al. 2000), whereas the protein was still found in lysosomes. Depletion of clathrin in HeLa cells did result in increased levels of LAMPs at the cell surface, but not a complete redistribution of LAMPs to the plasma membrane (Janvier and Bonifacino 2005), indicating the existence of a direct TGN-to-lysosome pathway independent of clathrin (Karlsson and Carlsson 1998). Interestingly, depletion of AP-1 in HeLa cells, like in mice, again had only modest effects on LAMP transport over the surface (Janvier and Bonifacino 2005). Together, these data indicate that in addition to AP-1 and clathrin, other factors might be involved in direct TGN-to-lysosome transport of LAMPs.

The presence of a clathrin-independent TGN-to-endosome pathway was also indicated by studies on cells that present antigens, like B lymphocytes, macrophages and dendritic cells, in the context of major histocompatibility complex (MHC) class II molecules (Fig. 3c). The newly synthesized MHC II molecules are transported from the TGN either via the plasma membrane or directly to socalled MHC II loading compartments (MIICs) that are lysosome-related organelles representing early and late endosomes in these cells (Kleijmeer et al. 1997). For proper transport of the integral membrane protein MHC II from TGN to MIICs, association with the type 2 transmembrane protein, invariant chain (Cresswell 1996), is important. Invariant chain contains [DE]XXX[LI]-type signals in its C-terminus, but also the cytoplasmic tail of class II was found to contain endosomal sorting information (Bakke and Nordeng 1999; Bonifacino and Traub 2003). The TGN-toendosome pathway of MHC II/invariant chain was studied in detail in B lymphoblasts by a combined biochemical and immuno-EM approach (Glickman et al. 1996). This revealed that MHC II, together with cathepsin D, in both normal and I-cell disease B lymphoblasts entered TGN exit domains that did not contain AP-1 or clathrin and were devoid of CD-MPR. Further studies are required to establish the molecular machinery of this pathway.

Interestingly, a recent study linked the TGN exit of lysosomal membrane proteins to GGA3, the same component involved in the exit of MPRs. GGAs are monoubiquitinated at their GAT (GGA and TOM) domain, which supports the idea that ubiquitin is a universal sorting signal, acting at various intracellular sites. The lysosomal-associated protein transmembrane-5 (LAPTM5), which is specifically expressed in hematopoietic cells, associates in the TGN with both the ubiquitin ligase Nedd4 and GGA3 (Pak et al. 2006). This association is required for efficient targeting of LAPTM5 to lysosomes and indicates that ubiquitination of GGA3 is possibly accomplished by Nedd4. The finding that GGAs can be involved in TGN-to-lysosome transport of a lysosomal membrane protein might explain the mild effect of AP-1 knockdown. Clearly, further studies are required to clarify this direct TGN-to-endosome transport pathway of lysosomal membrane proteins.

\section{The early endosome: from CURL to tubular sorting endosome}

The combined data on TGN-to-endosome transport of lysosomal hydrolases and lysosomal membrane proteins suggest the existence of multiple TGN exits for direct delivery to the endosomal system (Fig. 3c). There may be several reasons for such different pathways. For example, they allow custom tailored regulation of the delivery of distinct types of cargoes and provide a back-up system in case a given pathway is no longer available (such as in I-cell disease). The existence of alternative TGN-to-endosome pathways would also allow different cargoes to enter the endo-lysosomal system at distinct stages, which may coincide with their function and mode of sorting. In addition to understanding TGN exits, it is therefore equally important to define the recipient endo-lysosomal intermediates in lysosome biogenesis. With the refining of EM techniques, our understanding of the endo-lysosomal system has equally evolved. The technique that we now know as 'classical' EM, i.e. thin sections of plastic-embedded samples of chemically fixed cells, allowed our first acquaintance with the fascinating complexity of the cell's inner world. Immunocytochemistry added another dimension by allowing the 
localization of enzymatic activities to specific compartments (as illustrated for acid phosphatase). The next step was the development of immunocytochemical procedures, which greatly increased the repertoire of proteins that can be visualized in the cell.

One of the first published examples of immuno-EM also marked a major leap in our understanding of the endo-lysosomal system; i.e. the identification of the early endosome as sorting device. In 1983, a novel immuno-EM technique was introduced by Hans Geuze and Jan Slot, in which differentially sized gold particles were used to simultaneously localize two distinct proteins. By applying this technique to visualize a ligand-asialoglycoprotein (ASGP), which is endocytosed by liver cells for transport to lysosomes-as well as its receptor (ASGPR, which recycles after endocytosis), they for the first time visualized a proteinsorting event. The ASGPR was found in tubular membranes that lacked ASGP and were connected to vacuoles that were enriched for ASGP but depleted of ASGPR (Geuze et al. 1983) (Fig. 6, left panel). The ASGPR-containing tubules were implicated in the recycling of the ASGPR to the plasma membrane, and the ASGP-containing vacuoles were defined as 'precursor compartments en route to the lysosome'. The entire compartment was called 'CURL': 'compartment of uncoupling receptor and ligand'.

Over the years, it became clear that CURL was involved in the sorting of multiple types of proteins and the modern structural equivalent of CURL is the early endosome. Indeed, the early endosome is the major cellular site, where cargo destined for recycling is sorted from cargo en route to late endosomes and lysosomes. To indicate this, early endosomes are often subdivided into the globular "vacuolar or sorting' endosome (Fig. 3b), whereas the associated tubules were indicated as 'recycling tubules' or 'recycling endosomes'. However, recent studies provided accumulating evidence that early endosome-associated tubules are more than just transport intermediates for recycling cargo; they are also actively involved in sorting (Fig. 3b).

With the increasing number of antibodies against distinct types of cargoes and by optimizing immuno-EM techniques (Slot and Geuze 2007), it became possible to localize less abundant cargoes. This revealed that at steady state conditions minor amounts of LAMP- 1 and LAMP- 2 are found in the early endosome-associated tubules (Fig. 6, right panel). The importance of this localization became apparent from studies on the pigmentation-bleeding disorder HermanskyPudlak-syndrome-2 (HPS-2). Cells from HPS-2 patients lack a functional AP-3 adaptor complex and show an increased transport of lysosomal membrane proteins over the plasma membrane (dell'Angelica et al. 1999). A combination of biochemical and immuno-EM approaches revealed that AP-3 mediates the exit of lysosomal membrane proteins from the early endosome-associated tubules, most likely for transport to late endosomes or lysosomes (dell'Angelica et al. 1998; Peden et al. 2004) (Fig. 3b). Impairment of AP-3 function results in an increased cycling of lysosomal membrane proteins between early endosomes and plasma membrane (Peden et al. 2004), which explains the increased levels of lysosomal membrane proteins at the plasma membrane of HPS-2 cells. Importantly, early endosomes can be reached by lysosomal membrane proteins via the plasma membrane, but possibly also via a direct pathway from the TGN. This may explain why in the literature AP-3 has been implicated in the direct as well as indirect
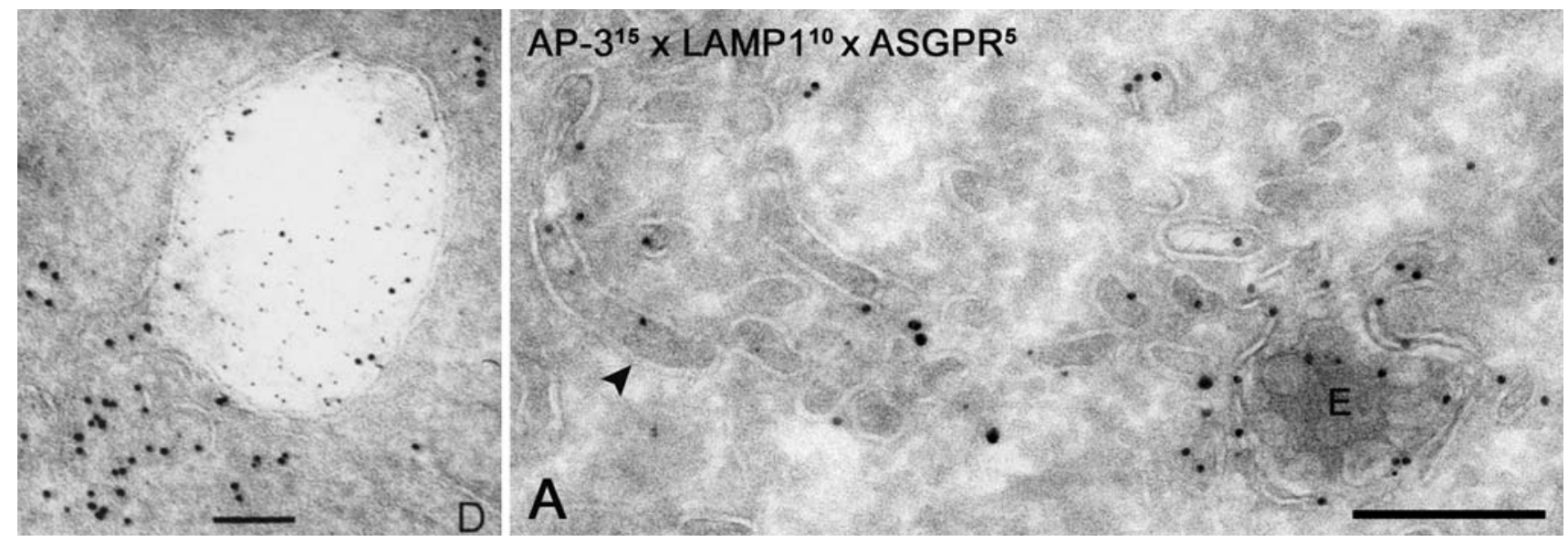

Fig. 6 From CURL to tubular sorting endosome. Left panel reproduction of the first electron micrograph using double-immunogold labeling, showing the uncoupling of a ligand (asialoglycoprotein (ASGP), indicated by $5 \mathrm{~nm}$ gold particles) from its receptor (indicated by $15 \mathrm{~nm}$ gold particles) in early endosomes, at that time called CURL (compartment for uncoupling receptor and ligand). The ASGP receptor is found in tubules implicated in its recycling, whereas ASGP en route to lyso- somes remains in the vacuole. Originally published by Geuze et al. (1983). Right panel, reproduction from Peden et al. (2004), showing by triple labeling that the adaptor protein AP-3 (15 nm gold particles), the lysosomal membrane protein $L A M P-1$ (10 nm gold particles) and the recycling ASGP receptor (5 $\mathrm{nm}$ gold particles) co-localize in the tubules emanating from endosomal vacuoles. This work gave rise to the concept of the tubular sorting endosome 
pathway to lysosomes (Ihrke et al. 2004; Rous et al. 2002). In melanocytes, AP-3 also mediates a pathway from early endosomes to melanosomes, which are lysosome-related organelles (Theos et al. 2005).

Importantly, by multiple double- and triple immunogold labellings, it was shown that a particular early endosomeassociated tubule could contain the recycling proteins $\mathrm{Tf}$ and ASGPR, the CD and CI-MPR, and LAMP-1 and LAMP-2. In addition, one single tubule could display multiple budding profiles that were positive for either the adaptor complex AP-1 or AP-3 (Peden et al. 2004). AP-1 on endosomal tubules has been implicated in the retrograde transport of the CD-MPR and of the Shiga toxin B subunit to the TGN (Meyer et al. 2000), as well as recycling of internalized Tf (Mallard et al. 1998; van Dam and Stoorvogel 2002). The presence of distinct types of recycling proteins and the association of multiple adaptor complexes indicated that the early endosome-associated tubules mediate sorting of cargo proteins to distinct destinations in the cell, i.e. plasma membrane, TGN and late endosomes or lysosomes. Therefore, these AP-3 positive compartments were introduced as tubular sorting endosomes (Figs. 3b and 6, right panel) (Peden et al. 2004). A recent review of Bonifacino and Rojas extends this concept (indicated here as 'tubular endosomal network'), by ascribing all protein machinery currently known to be involved in endosome-toTGN transport to distinct exits of the tubular sorting endosome (Bonifacino and Rojas 2006).

Together, the available data launch the concept of a twostep rocket. In the first step, at the vacuolar domain of early endosomes, proteins destined for late endosomes-lysosomes are sorted from recycling proteins that accumulate in the attached tubules. Then, in the second step, taking place in the tubular sorting endosome, recycling proteins are sorted out to distinct destinations in the cell. Within this model, the recycling endosomes are one type of transport intermediate that evolve from the tubular sorting endosomes, mediating the recycling of cargo to the plasma membrane (Fig. 3b).

\section{Multiple sorting events at the early endosomal limiting membrane}

Despite the relatively simple and attractive concept of the two-step rocket, sorting at the early endosomes displays another level of complexity; recycling carriers not only evolve from tubular sorting endosomes, but also from endosomal vacuoles. A recent study showed the formation of so-called endosome-to-TGN carriers (ETCs) from the limiting membrane of early endosomal vacuoles (Fig. 3b) (Mari et al. 2007). These ETCs are so far specifically involved in the endosome-to-TGN recycling of lysosomal protein receptors, i.e. the CD- and CI-MPRs and sortilin. Importantly, ETCs constitute an entirely different population of recycling carriers than those emanating from the tubular sorting endosome. With the exception of the MPRs, ETCs are devoid of any of the cargo or machinery proteins found in the tubular sorting endosome. The associated machinery proteins of ETCs are SNX1, SNX2 (Carlton et al. 2004, 2005; Mari et al. 2007) and hVps26p (Arighi et al. 2004; Mari, personal communication). ETCs also differ from tubular sorting endosomes by morphology. By 3D-tomographic analyses, ETCs were identified as nonbranched, short tubules and vesicles, not organized in a reticulum.

Apart from segregating proteins into tubular sorting endosomes and ETCs, the limiting membrane of early endosomal vacuoles is involved in a third protein sorting event; i.e. segregation of proteins into a characteristic bilayered coated area that is involved in protein sorting into ILVs (Fig. 3b, see also below) (Bonifacino and Rojas 2006; Peden et al. 2004; Raiborg et al. 2002; Raposo et al. 2001; Sachse et al. 2002b). Thus, proteins present in early endosomal vacuoles may be sorted to at least three types of specialized sorting domains: tubular sorting endosomes, ETC or the bilayered coat. The formation of two types of exits from the non-coated regions of the early endosomal vacuoles predicts the existence of complementary molecular machineries that specifically recruit cargo to either of these recycling compartments (i.e. ETC or tubular sorting endosome). Future investigations are needed to further unveil the components of these machineries.

\section{Sorting to late endosomes and lysosomes}

The default pathway for molecules entering early endosomes is recycling back to the plasma membrane, a pathway that starts with the segregation of cargo into the tubular extensions of the early endosomes (Draye et al. 1988; Yamashiro et al. 1984). Endocytosed cargo from the plasma membrane that is not destined for recycling requires active sorting to late endosomes/lysosomes, a process mostly mediated by inclusion into ILVs (Gruenberg and Stenmark 2004; Katzmann et al. 2002; Sachse et al. 2002b).

Protein sorting into ILVs is critical for growth factors and their receptors, such as growth hormone $(\mathrm{GH})$ (Sachse et al. 2002b) and epidermal growth factor (EGF) (Raiborg et al. 2003; Urbe et al. 2003). Sorting into ILVs segregates these ligand-receptor complexes from the cytoplasm, thereby terminating signaling. ILV sorting requires ubiquitination and involves among others the cytoplasmic proteins Hrs and STAM (Bache et al. 2003b; Raiborg et al. 2001, 2002; Urbe et al. 2003). By immuno-EM, it was shown that at the limiting membrane of the early endosomal 
vacuole the GHR and EGFR are concentrated in flat, bilayered coated areas with a fuzzy outer layer of clathrin and a dense inner layer of unknown protein composition. These bilayered coated domains were enriched in Hrs (Sachse et al. 2002b). These findings led to the proposition of the 'sorting-by-retention' model for endosomal sorting (Sachse et al. 2002b). This model describes that receptorligand complexes prior to their incorporation into ILVs are retained and concentrated in the bilayered coated areas of endosomal vacuoles, whereas recycling proteins pass through the vacuolar-limiting membrane and follow the bulk flow route towards recycling endosomes. A recent study showed that the recruitment of clathrin is responsible for concentrating Hrs in these endosomal microdomains, reinforcing an active role for clathrin in protein retention (Raiborg et al. 2006).

Downstream of Hrs, the targeting of ubiquitinated receptors into ILVs requires the 'endosomal sorting complexes required for transport' (ESCRT)-1, -2 and -3 in concert with Alix/AIP-4 and the AAA-ATPase (hVps4). hVps4 is required for disassembly and recycling of ESCRT complexes (Babst 2005; Bache et al. 2003a; Katzmann et al. 2003) and interestingly, also for the disassembly of the bilayered coat (Sachse et al. 2004). Impairment of hVps4p function gives rise to an elongated coat and decreased formation of ILVs, indicating that coat disassembly is required for the inward budding process to proceed (Sachse et al. 2004). Indeed, 3D-electron tomography of early endosomes showed that inward budding of ILVs is mostly seen at the edges of the coats (Murk et al. 2003). Notably, the sortingby-retention model proposes a novel role for clathrin in addition to its role in the formation of transport vesicles, i.e. defining endosomal subdomains involved in protein retention.

\section{Future developments}

With the increasing number of molecular markers of endosomes and lysosomes, there is a growing awareness that distinct populations of endosomes and perhaps even lysosomes, with different functions, can coexist within one cell (Bökel et al. 2006; Lakadamyali et al. 2006; Möbius et al. 2003; White et al. 2006). For example, ILVs enriched in the lipid lysobisphosphatidic acid (LBPA) are found in distinct MVBs from those enriched in cholesterol (Möbius et al. 2003). Another example is illustrated in Fig. 7 showing three seemingly identical late endosomes, of which only two are reached by endocytosed BSA-gold after $3 \mathrm{~h}$ of uptake. One explanation is that cargo drives the formation of specific endocytic compartments. For example, addition of EGF to cells results in the specific increase of the type of MVBs that do not contain LBPA (White et al. 2006).

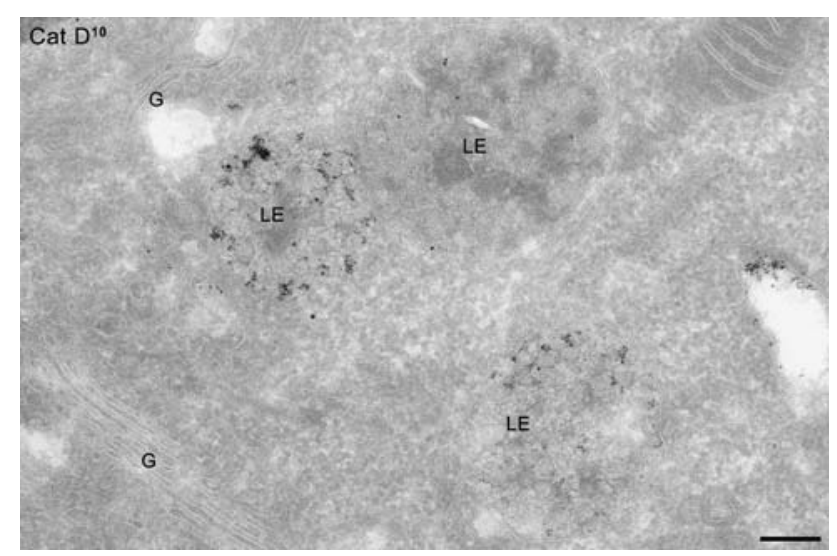

Fig. 7 Electron micrograph illustrating the heterogeneity of late endosomes $(L E)$. HepG2 cells were allowed to internalize bovine serum albumin (BSA) conjugated to $5 \mathrm{~nm}$ gold particles (abundant labeling) for $3 \mathrm{~h}$ and processed for immuno-EM of cathepsin $D(10 \mathrm{~nm}$ gold particles, scarce labeling). Three seemingly identical late endosomes containing multiple ILVs and partially degraded material are shown, two of which are heavily loaded with BSA-gold, whereas the upper one is devoid of the endocytic tracer. G Golgi stacks; Bar $200 \mathrm{~nm}$

Formation of cargo-dependent carriers can start at the plasma membrane. The recent identification of clathrinindependent endocytosis, as well as the discovery of cargo specific adaptors that lead to clathrin-coated pit formationeither in conjunction with or independent of AP-2-illustrates that alternative endocytic pathways can arise from the plasma membrane. If and how these pathways converge at the endosomal level is presently unclear (Benmerah and Lamaze 2007). EM is an indispensable tool to search for cargo-specific endosomal compartments, since by fluorescence microscopy only the labelled compartment is visible and a nearby compartment negative for the cargo under study will remain unseen.

Another point of interest is that not all cargo might be recruited to ILVs by the same mechanism. Both in yeast (Bilodeau et al. 2002; Epple et al. 2003) and mammalian cells (Hislop et al. 2004), examples of cargoes are described that do not require direct ubiquitination. In case of the melanosomal protein Pmel17, which is also targeted to ILVs independently of ubiquitin and Hrs, two N-terminal lumenal subdomains seem necessary and sufficient for efficient transport (Theos et al. 2006). Possibly, these nonubiquitinated cargoes associate with others for their association with the ESCRT machinery, but perhaps they use an alternative mechanism. Interesting in this respect is that LBPA can induce ILV formation in liposomes, in the absence of protein, suggesting that lipid-driven and ESCRT-dependent pathways may coexist (Matsuo et al. 2004). Also the lysosomal targeting of LAMP-1 and LAMP-2 remains an interesting open question, since these proteins are predominantly located on the limiting membranes of late endosomes and lysosomes, and incorporation 
into ILVs seems therefore not involved. By a more detailed characterization of the distinct endosomal maturation stages (Mari et al. 2007), it will be feasible to obtain a more accurate definition of the stage in which a specific cargo enters or exits the endo-lysosomal system. One of the questions that is currently addressed in our lab is whether lysosomal membrane proteins can travel directly to late endosomes or lysosomes, thereby bypassing the need of ESCRT sorting machinery.

Finally, with the development of live cell imaging methods and correlative live cell imaging EM, a unique tool is provided to integrate dynamic parameters with ultrastructural protein localization studies, which opens a whole new field of analysis.

Acknowledgments We want to thank the scientists to whom we refer here for their often groundbreaking contributions to the understanding of the complexity and beauty of the endo-lysosomal system and apologize to those many others whose work we were not able to discuss. We also want to thank our colleagues of the Department of Cell Biology for the many scientific interactions and fruitful discussions. We express our special thanks to Marc van Peski for his help with preparation of the figures and to Maaike Pols, Muriel Mari and Hans Geuze for critically reading our manuscript. EvM and JK are supported by VICI grant 918.56 .611 of the Netherlands Organization for Scientific research (NWO).

Open Access This article is distributed under the terms of the Creative Commons Attribution Noncommercial License which permits any noncommercial use, distribution, and reproduction in any medium, provided the original author(s) and source are credited.

\section{References}

Aerts JM, Schram AW, Strijland A, van Weely S, Jonsson LM, Tager JM, Sorrell SH, Ginns EI, Barranger JA, Murray GJ (1988) Glucocerebrosidase, a lysosomal enzyme that does not undergo oligosaccharide phosphorylation. Biochim Biophys Acta 964:303308

Arighi CN, Hartnell LM, Aguilar RC, Haft CR, Bonifacino JS (2004) Role of the mammalian retromer in sorting of the cation-independent mannose 6-phosphate receptor. J Cell Biol 165:123-133

Babst M (2005) A protein's final ESCRT. Traffic 6:2-9

Bache KG, Brech A, Mehlum A, Stenmark H (2003a) Hrs regulates multivesicular body formation via ESCRT recruitment to endosomes. J Cell Biol 162:435-442

Bache KG, Raiborg C, Mehlum A, Stenmark H (2003b) STAM and Hrs are subunits of a multivalent ubiquitin-binding complex on early endosomes. J Biol Chem 278:12513-12521

Bainton DF (1981) The discovery of lysosomes. J Cell Biol 91:66s-76s

Bakke O, Nordeng TW (1999) Intracellular traffic to compartments for MHC class II peptide loading: signals for endosomal and polarized sorting. Immunol Rev 172:171-187

Barka T, Anderson PJ (1962) Histochemical methods for acid phosphatase using hexazonium pararosanilin as coupler. J Histochem Cytochem 10:741-753

Benmerah A, Lamaze C (2007) Clathrin-coated pits: vive la difference? Traffic 8:970-982

Bilodeau PS, Urbanowski JL, Winistorfer SC, Piper RC (2002) The Vps27p Hse1p complex binds ubiquitin and mediates endosomal protein sorting. Nat Cell Biol 4:534-539
Bleekemolen JE, Stein M, von Figura K, Slot JW, Geuze HJ (1988) The two mannose 6-phosphate receptors have almost identical subcellular distributions in U937 monocytes. Eur J Cell Biol 47:366-372

Bökel C, Schwabedissen A, Entchev E, Renaud O, González-Gaitán M (2006) Sara endosomes and the maintenance of Dpp signaling levels across mitosis. Science 314:1135-1139

Boman AL, Zhang C, Zhu X, Kahn RA (2000) A family of ADP-ribosylation factor effectors that can alter membrane transport through the trans-Golgi. Mol Biol Cell 11:1241-1255

Bonifacino JS, Rojas R (2006) Retrograde transport from endosomes to the trans-Golgi network. Nat Rev Mol Cell Biol 7:568-579

Bonifacino JS, Traub LM (2003) Signals for sorting of transmembrane proteins to endosomes and lysosomes. Annu Rev Biochem 72:395-447

Carlsson SR, Fukuda M (1992) The lysosomal membrane glycoprotein lamp-1 is transported to lysosomes by two alternative pathways. Arch Biochem Biophys 296:630-639

Carlton J, Bujny M, Peter BJ, Oorschot VM, Rutherford A, Mellor H, Klumperman J, McMahon HT, Cullen PJ (2004) Sorting nexin-1 mediates tubular endosome-to-TGN transport through coincidence sensing of high- curvature membranes and 3-phosphoinositides. Curr Biol 14:1791-1800

Carlton JG, Bujny MV, Peter BJ, Oorschot VM, Rutherford A, Arkell RS, Klumperman J, McMahon HT, Cullen PJ (2005) Sorting nexin-2 is associated with tubular elements of the early endosome, but is not essential for retromer-mediated endosome-to-TGN transport. J Cell Sci 118:4527-4539

Conner SD, Schmid SL (2003) Regulated portals of entry into the cell. Nature 422:37-44

Cresswell P (1996) Invariant chain structure and MHC class II function. Cell 84:505-507

de Duve C (1959) In: Hayashi T (ed) Subcellular particles. Ronald press, New York, pp 128-159

de Duve C (2005) The lysosome turns fifty. Nat Cell Biol 7:847-849

de Duve C, Pressman BC, Gianetto R, Wattiaux R, Appelmans F (1955) Tissue fractionation studies. 6. Intracellular distribution patterns of enzymes in rat-liver tissue. Biochem J 60:604-617

dell'Angelica EC, Klumperman J, Stoorvogel W, Bonifacino JS (1998) Association of the AP-3 adaptor complex with clathrin. Science 280:431-434

dell'Angelica EC, Mullins C, Caplan S, Bonifacino JS (2000a) Lysosome-related organelles. FASEB J 14:1265-1278

dell'Angelica EC, Puertollano R, Mullins C, Aguilar RC, Vargas JD, Hartnell LM, Bonifacino JS (2000b) GGAs: a family of ADP ribosylation factor-binding proteins related to adaptors and associated with the Golgi complex. J Cell Biol 149:81-94

dell'Angelica EC, Shotelersuk V, Aguilar RC, Gahl WA, Bonifacino JS (1999) Altered trafficking of lysosomal proteins in Hermansky-Pudlak syndrome due to mutations in the beta $3 \mathrm{~A}$ subunit of the AP-3 adaptor. Mol Cell 3:11-21

Dittmer F, Ulbrich EJ, Hafner A, Schmahl W, Meister T, Pohlmann $R$, von Figura K (1999) Alternative mechanisms for trafficking of lysosomal enzymes in mannose 6-phosphate receptor-deficient mice are cell type-specific. J Cell Sci 112(Pt 10):15911597

Doray B, Ghosh P, Griffith J, Geuze HJ, Kornfeld S (2002) Cooperation of GGAs and AP-1 in packaging MPRs at the trans-Golgi network. Science 297:1700-1703

Draye JP, Courtoy PJ, Quintart J, Baudhuin P (1988) A quantitative model of traffic between plasma membrane and secondary lysosomes: evaluation of inflow, lateral diffusion, and degradation. J Cell Biol 107:2109-2115

Epple UD, Eskelinen EL, Thumm M (2003) Intravacuolar membrane lysis in Saccharomyces cerevisiae. Does vacuolar targeting of Cvt17/Aut5p affect its function? J Biol Chem 278:7810-7821 
Erickson AH, Ginns EI, Barranger JA (1985) Biosynthesis of the lysosomal enzyme glucocerebrosidase. J Biol Chem 260:1431914324

Eskelinen EL (2005) Maturation of autophagic vacuoles in mammalian cells. Autophagy 1:1-10

Eskelinen EL, Tanaka Y, Saftig P (2003) At the acidic edge: emerging functions for lysosomal membrane proteins. Trends Cell Biol 13:137-145

Essner E, Novikoff AB (1961) Localization of acid phosphatase activity in hepatic lysosomes by means of electron microscopy. J Biophys Biochem Cytol 9:773-784

Futerman AH, van Meer G (2004) The cell biology of lysosomal storage disorders. Nat Rev Mol Cell Biol 5:554-565

Futter CE, Pearse A, Hewlett LJ, Hopkins CR (1996) Multivesicular endosomes containing internalized EGF-EGF receptor complexes mature and then fuse directly with lysosomes. J Cell Biol 132:1011-1023

Gelfman CM, Vogel P, Issa TM, Turner CA, Lee WS, Kornfeld S, Rice DS (2007) Mice lacking alpha/beta subunits of GlcNAc-1-phosphotransferase exhibit growth retardation, retinal degeneration, and secretory cell lesions. Invest Ophthalmol Vis Sci 48:52215228

Geuze HJ, Slot JW, Strous GJ, Hasilik A, von Figura K (1984) Ultrastructural localization of the mannose 6-phosphate receptor in rat liver. J Cell Biol 98:2047-2054

Geuze HJ, Slot JW, Strous GJ, Hasilik A, von Figura K (1985) Possible pathways for lysosomal enzyme delivery. J Cell Biol 101:22532262

Geuze HJ, Slot JW, Strous GJ, Lodish HF, Schwartz AL (1983) Intracellular site of asialoglycoprotein receptor-ligand uncoupling: double-label immunoelectron microscopy during receptor-mediated endocytosis. Cell 32:277-287

Ghosh P, Dahms NM, Kornfeld S (2003a) Mannose 6-phosphate receptors: new twists in the tale. Nat Rev Mol Cell Biol 4:202-212

Ghosh P, Griffith J, Geuze HJ, Kornfeld S (2003b) Mammalian GGAs act together to sort mannose 6-phosphate receptors. J Cell Biol 163:755-766

Glickman JN, Morton PA, Slot JW, Kornfeld S, Geuze HJ (1996) The biogenesis of the MHC class II compartment in human I-cell disease B lymphoblasts. J Cell Biol 132:769-785

Gomori G (1952) Microscopic histochemistry. Principle and practice. University of Chicago Press, Chicago, p 137

Griffiths G, Hoflack B, Simons K, Mellman I, Kornfeld S (1988) The mannose 6-phosphate receptor and the biogenesis of lysosomes. Cell 52:329-341

Gruenberg J, Stenmark H (2004) The biogenesis of multivesicular endosomes. Nat Rev Mol Cell Biol 5:317-323

Hasilik A, Waheed A, von Figura K (1981) Enzymatic phosphorylation of lysosomal enzymes in the presence of UDP-N-acetylglucosamine. Absence of the activity in I-cell fibroblasts. Biochem Biophys Res Commun 98:761-767

Hirst J, Lui WW, Bright NA, Totty N, Seaman MN, Robinson MS (2000) A family of proteins with gamma-adaptin and VHS domains that facilitate trafficking between the trans-Golgi network and the vacuole/lysosome. J Cell Biol 149:67-80

Hislop JN, Marley A, von Zastrow M (2004) Role of mammalian vacuolar protein-sorting proteins in endocytic trafficking of a nonubiquitinated $\mathrm{G}$ protein-coupled receptor to lysosomes. J Biol Chem 279:22522-22531

Hoflack B, Kornfeld S (1985a) Lysosomal enzyme binding to mouse P388D1 macrophage membranes lacking the 215-kDa mannose 6-phosphate receptor: evidence for the existence of a second mannose 6-phosphate receptor. Proc Natl Acad Sci USA $82: 4428-4432$

Hoflack B, Kornfeld S (1985b) Purification and characterization of a cation-dependent mannose 6-phosphate receptor from murine
P388D1 macrophages and bovine liver. J Biol Chem 260:1200812014

Holt SJ (1959) Factors governing the validity of staining methods for enzymes, and their bearing upon the Gomori acid phosphatase technique. Exp Cell Res Suppl 7:1-27

Höning S, Griffith J, Geuze HJ, Hunziker W (1996) The tyrosine-based lysosomal targeting signal in lamp-1 mediates sorting into Golgiderived clathrin-coated vesicles. EMBO J 15:5230-5239

Hunziker W, Geuze HJ (1996) Intracellular trafficking of lysosomal membrane proteins. Bioessays 18:379-389

Ihrke G, Kyttala A, Russell MRG, Rous BA, Luzio JP (2004) Differential use of two AP-3-mediated pathways by lysosomal membrane proteins. Traffic 5:946-962

Janvier K, Bonifacino JS (2005) Role of the endocytic machinery in the sorting of lysosome-associated membrane proteins. Mol Biol Cell 16:4231-4242

Karlsson K, Carlsson SR (1998) Sorting of lysosomal membrane glycoproteins lamp-1 and lamp- 2 into vesicles distinct from mannose 6-phosphate receptor/gamma-adaptin vesicles at the trans-Golgi network. J Biol Chem 273:18966-18973

Katzmann DJ, Odorizzi G, Emr SD (2002) Receptor downregulation and multivesicular-body sorting. Nat Rev Mol Cell Biol 3:893905

Katzmann DJ, Stefan CJ, Babst M, Emr SD (2003) Vps27 recruits ESCRT machinery to endosomes during MVB sorting. J Cell Biol 162:413-423

Kirkham M, Parton RG (2005) Clathrin-independent endocytosis: new insights into caveolae and non-caveolar lipid raft carriers. Biochim Biophys Acta 1746:349-363

Kleijmeer MJ, Morkowski S, Griffith JM, Rudensky AY, Geuze HJ (1997) Major histocompatibility complex class II compartments in human and mouse B lymphoblasts represent conventional endocytic compartments. J Cell Biol 139:639-649

Klionsky DJ (2007) Autophagy: from phenomenology to molecular understanding in less than a decade. Nat Rev Mol Cell Biol 8:931-937

Klumperman J, Hille A, Veenendaal T, Oorschot V, Stoorvogel W, von Figura K, Geuze HJ (1993) Differences in the endosomal distributions of the two mannose 6-phosphate receptors. J Cell Biol 121:997-1010

Klumperman J, Kuliawat R, Griffith JM, Geuze HJ, Arvan P (1998) Mannose 6-phosphate receptors are sorted from immature secretory granules via adaptor protein AP-1, clathrin, and syntaxin 6positive vesicles. J Cell Biol 141:359-371

Kornfeld S, Mellman I (1989) The biogenesis of lysosomes. Annu Rev Cell Biol 5:483-525

Kroemer G, Jäättelä M (2005) Lysosomes and autophagy in cell death control. Nat Rev Cancer 5:886-897

Lakadamyali M, Rust MJ, Zhuang X (2006) Ligands for clathrin-mediated endocytosis are differentially sorted into distinct populations of early endosomes. Cell 124:997-1009

Lefrancois S, Zeng J, Hassan AJ, Canuel M, Morales CR (2003) The lysosomal trafficking of sphingolipid activator proteins (SAPs) is mediated by sortilin. EMBO J 22:6430-6437

Little L, Alcouloumre M, Drotar AM, Herman S, Robertson R, Yeh RY, Miller AL (1987) Properties of $N$-acetylglucosamine-1-phosphotransferase from human lymphoblasts. Biochem J 248:151-159

Luzio JP, Pryor PR, Bright NA (2007) Lysosomes: fusion and function. Nat Rev Mol Cell Biol 8:622-632

Mallard F, Antony C, Tenza D, Salamero J, Goud B, Johannes L (1998) Direct pathway from early/recycling endosomes to the Golgi apparatus revealed through the study of shiga toxin B-fragment transport. J Cell Biol 143:973-990

Marcusson EG, Horazdovsky BF, Cereghino JL, Gharakhanian E, Emr SD (1994) The sorting receptor for yeast vacuolar carboxypeptidase $\mathrm{Y}$ is encoded by the VPS10 gene. Cell 77:579-586 
Mari M, Bujny MV, Zeuschner D, Geerts WJC, Griffith J, Petersen CM, Cullen PJ, Klumperman J, Geuze HJ (2008) SNX1 defines an early endosomal recycling exit for sortilin and mannose 6phosphate receptors. Traffic. 2008 Jan 11 [Epub ahead of print]

Marsh M, Schmid S, Kern H, Harms E, Male P, Mellman I, Helenius A (1987) Rapid analytical and preparative isolation of functional endosomes by free flow electrophoresis. J Cell Biol 104:875-886

Matsuo H, Chevallier J, Mayran N, Le Blanc I, Ferguson C, Faure J, Blanc NS, Matile S, Dubochet J, Sadoul R et al (2004) Role of LBPA and Alix in multivesicular liposome formation and endosome organization. Science 303:531-534

Mayor S, Pagano RE (2007) Pathways of clathrin-independent endocytosis. Nat Rev Mol Cell Biol 8:603-612

Meyer C, Zizioli D, Lausmann S, Eskelinen EL, Hamann J, Saftig P, von Figura K, Schu P (2000) $\mu 1 \mathrm{~A}$-adaptin-deficient mice: lethality, loss of AP-1 binding and rerouting of mannose 6-phosphate receptors. EMBO J 19:2193-2203

Möbius W, van Donselaar E, Ohno-Iwashita Y, Shimada Y, Heijnen HF, Slot JW, Geuze HJ (2003) Recycling compartments and the internal vesicles of multivesicular bodies harbor most of the cholesterol found in the endocytic pathway. Traffic 4:222-231

Mohamed MM, Sloane BF (2006) Cysteine cathepsins: multifunctional enzymes in cancer. Nat Rev Cancer 6:764-775

Murk JL, Humbel BM, Ziese U, Griffith JM, Posthuma G, Slot JW, Koster AJ, Verkleij AJ, Geuze HJ, Kleijmeer MJ (2003) Endosomal compartmentalization in three dimensions: implications for membrane fusion. Proc Natl Acad Sci USA 100:13332-13337

Nichols B (2003) Caveosomes and endocytosis of lipid rafts. J Cell Sci 116:4707-4714

Nixon RA (2005) Endosome function and dysfunction in Alzheimer's disease and other neurodegenerative diseases. Neurobiol Aging 26:373-382

Novikoff AB (1961) In: Brachet J, Mirsky AE (eds) The cell. Academic Press, New York, pp 423-488

Novikoff AB, Beaufay H, de Duve C (1956) Electron microscopy of lysosomerich fractions from rat liver. J Biophys Biochem Cytol 2:179-184

Obermüller S, Kiecke C, von Figura K, Höning S (2002) The tyrosine motifs of Lamp 1 and LAP determine their direct and indirect targetting to lysosomes. J Cell Sci 115:185-194

Owada M, Neufeld EF (1982) Is there a mechanism for introducing acid hydrolases into liver lysosomes that is independent of mannose 6-phosphate recognition? Evidence from I-cell disease. Biochem Biophys Res Commun 105:814-820

Pak Y, Glowacka WK, Bruce MC, Pham N, Rotin D (2006) Transport of LAPTM5 to lysosomes requires association with the ubiquitin ligase Nedd4, but not LAPTM5 ubiquitination. J Cell Biol 175:631-645

Peden AA, Oorschot V, Hesser BA, Austin CD, Scheller RH, Klumperman J (2004) Localization of the AP-3 adaptor complex defines a novel endosomal exit site for lysosomal membrane proteins. J Cell Biol 164:1065-1076

Peters C, Braun M, Weber B, Wendland M, Schmidt B, Pohlmann R, Waheed A, von Figura K (1990) Targeting of a lysosomal membrane protein: a tyrosine-containing endocytosis signal in the cytoplasmic tail of lysosomal acid phosphatase is necessary and sufficient for targeting to lysosomes. EMBO J 9:3497-3506

Pohlmann R, Krentler C, Schmidt B, Schroder W, Lorkowski G, Culley J, Mersmann G, Geier C, Waheed A, Gottschalk S et al (1988) Human lysosomal acid phosphatase: cloning, expression and chromosomal assignment. EMBO J 7:2343-2350

Poussu A, Lohi O, Lehto VP (2000) Vear, a novel Golgi-associated protein with VHS and gamma-adaptin "ear" domains. J Biol Chem 275:7176-7183

Puertollano R, van der Wel NN, Greene LE, Eisenberg E, Peters PJ, Bonifacino JS (2003) Morphology and dynamics of clathrin/
GGA1-coated carriers budding from the trans-Golgi network. Mol Biol Cell 14:1545-1557

Qian M, Sleat DE, Zheng H, Moore D, Lobel P (2008) Proteomics analysis of serum from mutant mice reveals lysosomal proteins selectively transported by each of the two mannose 6-phosphate receptors. Mol Cell Proteomics 7:58-70

Raiborg C, Bache KG, Gillooly DJ, Madshus IH, Stang E, Stenmark H (2002) Hrs sorts ubiquitinated proteins into clathrin-coated microdomains of early endosomes. Nat Cell Biol 4:394-398

Raiborg C, Bache KG, Mehlum A, Stang E, Stenmark H (2001) Hrs recruits clathrin to early endosomes. EMBO J 20:5008-5021

Raiborg C, Rusten TE, Stenmark H (2003) Protein sorting into multivesicular endosomes. Curr Opin Cell Biol 15:446-455

Raiborg C, Wesche J, Malerod L, Stenmark H (2006) Flat clathrin coats on endosomes mediate degradative protein sorting by scaffolding Hrs in dynamic microdomains. J Cell Sci 119:2414-2424

Raposo G, Marks MS, Cutler DF (2007) Lysosome-related organelles: driving post-Golgi compartments into specialisation. Curr Opin Cell Biol 19:394-401

Raposo G, Tenza D, Murphy DM, Berson JF, Marks MS (2001) Distinct protein sorting and localization to premelanosomes, melanosomes, and lysosomes in pigmented melanocytic cells. J Cell Biol 152:809-824

Reczek D, Schwake M, Schröder J, Hughes H, Blanz J, Jin X, Brondyk W, van Patten S, Edmunds T, Saftig P (2007) LIMP-2 is a receptor for lysosomal mannose-6-phosphate-independent targeting of beta-glucocerebrosidase. Cell 131:770-783

Reitman ML, Varki A, Kornfeld S (1981) Fibroblasts from patients with I-cell disease and pseudo-Hurler polydystrophy are deficient in uridine 5'-diphosphate- $N$-acetylglucosamine: glycoprotein $N$ acetylglucosaminylphosphotransferase activity. J Clin Invest 67:1574-1579

Rijnboutt S, Aerts HM, Geuze HJ, Tager JM, Strous GJ (1991) Mannose 6-phosphate-independent membrane association of cathep$\sin \mathrm{D}$, glucocerebrosidase, and sphingolipid-activating protein in HepG2 cells. J Biol Chem 266:4862-4868

Rous BA, Reaves BJ, Ihrke G, Briggs JA, Gray SR, Stephens DJ, Banting G, Luzio JP (2002) Role of adaptor complex AP-3 in targeting wild-type and mutated CD63 to lysosomes. Mol Biol Cell 13:1071-1082

Sachse M, Ramm G, Strous G, Klumperman J (2002a) Endosomes: multipurpose designs for integrating housekeeping and specialized tasks. Histochem Cell Biol 117:91-104

Sachse M, Strous GJ, Klumperman J (2004) ATPase-deficient hVPS4 impairs formation of internal endosomal vesicles and stabilizes bilayered clathrin coats on endosomal vacuoles. J Cell Sci 117:1699-1708

Sachse M, Urbe S, Oorschot V, Strous GJ, Klumperman J (2002b) Bilayered clathrin coats on endosomal vacuoles are involved in protein sorting toward lysosomes. Mol Biol Cell 13:1313-1328

Saftig P, Tanaka Y, Lullmann-Rauch R, von Figura K (2001) Disease model: LAMP-2 enlightens Danon disease. Trends Mol Med 7:37-39

Sahagian GG, Distler J, Jourdian GW (1981) Characterization of a membrane-associated receptor from bovine liver that binds phosphomannosyl residues of bovine testicular beta-galactosidase. Proc Natl Acad Sci USA 78:4289-4293

Sleat DE, Lobel P (1997) Ligand binding specificities of the two mannose 6-phosphate receptors. J Biol Chem 272:731-738

Slot JW, Geuze HJ (2007) Cryosectioning and immunolabeling. Nat Protoc 2:2480-2491

Straus W (1954) Isolation and biochemical properties of droplets from the cells of rat kidney. J Biol Chem 207:745-755

Straus W (1956) Concentration of acid phosphatase, ribonuclease, desoxyribonuclease, beta-glucuronidase, and cathepsin in droplets 
isolated from the kidney cells of normal rats. J Biophys Biochem Cytol 2:513-521

Theos AC, Tenza D, Martina JA, Hurbain I, Peden AA, Sviderskaya EV, Stewart A, Robinson MS, Bennett DC, Cutler DF et al (2005) Functions of adaptor protein (AP)-3 and AP-1 in tyrosinase sorting from endosomes to melanosomes. Mol Biol Cell 16:53565372

Theos AC, Truschel ST, Tenza D, Hurbain I, Harper DC, Berson JF, Thomas PC, Raposo G, Marks MS (2006) A lumenal domaindependent pathway for sorting to intralumenal vesicles of multivesicular endosomes involved in organelle morphogenesis. Dev Cell 10:343-354

Urbe S, Sachse M, Row PE, Preisinger C, Barr FA, Strous G, Klumperman J, Clague MJ (2003) The UIM domain of Hrs couples receptor sorting to vesicle formation. J Cell Sci 116:4169-4179

van Dam EM, Stoorvogel W (2002) Dynamin-dependent transferrin receptor recycling by endosome-derived clathrin-coated vesicles. Mol Biol Cell 13:169-182

von Figura K (1991) Molecular recognition and targeting of lysosomal proteins. Curr Opin Cell Biol 3:642-646

Waheed A, Gottschalk S, Hille A, Krentler C, Pohlmann R, Braulke T, Hauser H, Geuze H, von Figura K (1988) Human lysosomal acid phosphatase is transported as a transmembrane protein to lysosomes in transfected baby hamster kidney cells. EMBO J 7:23512358

Waheed A, Pohlmann R, Hasilik A, von Figura K, van Elsen A, Leroy JG (1982) Deficiency of UDP- $N$-acetylglucosamine: lysosomal enzyme $N$-acetylglucosamine-1-phosphotransferase in organs of I-cell patients. Biochem Biophys Res Commun 105:1052-1058

Weaver TE, Na CL, Stahlman M (2002) Biogenesis of lamellar bodies, lysosome-related organelles involved in storage and secretion of pulmonary surfactant. Semin Cell Dev Biol 13:263-270

Westergaard UB, Kirkegaard K, Sorensen ES, Jacobsen C, Nielsen MS, Petersen CM, Madsen P (2005) SorCS3 does not require propeptide cleavage to bind nerve growth factor. FEBS Lett 579:1172-1176

White IJ, Bailey LM, Aghakhani MR, Moss SE, Futter CE (2006) EGF stimulates annexin 1-dependent inward vesiculation in a multivesicular endosome subpopulation. EMBO J 25:1-12

Yamashiro DJ, Tycko B, Fluss SR, Maxfield FR (1984) Segregation of transferrin to a mildly acidic ( $\mathrm{pH} 6.5$ ) para-Golgi compartment in the recycling pathway. Cell 37:789-800 